\title{
PROGRAMA DE COMPLIANCE E A LEI ANTICORRUPÇÃO ATUANDO NA RESPONSABILIDADE DE PESSOAS JURIDICAS
}

\section{COMPLIANCE PROGRAM AND ANTI-CORRUPTION LAW IN THE RESPONSIBILITY OF LEGAL ENTITIES}

\author{
Kaliny Katlin Pereira Da Silva ${ }^{1}$ \\ Sibéria Sales Queiroz de Lima²
}

\section{RESUMO}

No Brasil, de modo recente, emerge uma problemática, muito enraizada no país, a corrupção. Casos que envolvem escândalos de fraude e corrupção em instituições públicas e privadas têm sido noticiados destacando frequentemente os casos de desvio de verbas públicas. Diante, dessa realidade, foram desenvolvidas diversas operações de investigação, sendo que a mais conhecida a Operação Lava Jato. Em momento anterior referida operação, entrou em vigor a Lei Anticorrupção, um dispositivo legislativo que apresenta como objetivo punir atos ilícitos contra a administração pública, nos quais organizações serão responsabilizadas por práticas de lesão à administração pública nacional ou estrangeira. A lei foi regulamentada pelo Decreto $n^{-}$ 8.420/2015, que também regulamentou as regras para o acordo de Leniência. Cujo objetivo é compreender o programa de compliance na determinação da responsabilidade de pessoas jurídica no que tange a lei anticorrupção. A partir da pesquisa bibliográfica, descritiva e analítica, o artigo explanara um breve contexto histórico, e a relação do compliance com a Lei Anticorrupção. No que tange a lei anticorrupção, de que forma o programa de compliance pode ajudar na determinação de responsabilidade de pessoas jurídicas. Na presente pesquisa, observou se que a Lei Anticorrupção incentiva às empresas a adotarem procedimentos internos de controle. $\mathrm{A}$ lei garante que as empresas que incluírem o programa de Compliance em sua organização interna, ainda que, não consigam evitar que ocorram atos ilícitos, terão a tratamento diferenciado e punição atenuada. Diante dessa realidade, este trabalho buscou verificar como o Programa de Compliance, ajudará no controle interno das empresas.

\footnotetext{
${ }^{1}$ Bacharel em Direito pela Faculdade Católica do Tocantins. E-mail: kalinykps44@gmail.com ORCID https://orcid.org/0000-0002-3561-768X

${ }^{2}$ Mestrado em Educação pela Universidade de Brasília. Graduação em Direito e Letras. Tem experiência na área de Linguística, com ênfase em Sociolinguística e Dialetologia. Docente na Faculdade Católica do Tocantins. E- mail: siberia.lima@catolica-to.edu.br ORCID ID https://orcid.org/0000-0003-3579-3357
} 
PALAVRAS-CHAVE: Compliance. Lei Anticorrupção. Responsabilidade. Tributário.

\section{ABSTRACT}

In Brazil, in a recent way, urges a problematic, very deep in our country, the corruption. Cases involving frauds and corruption in public and private institutions have been in the news, frequently cases of detouring public money. In front of this reality, it was developed several research operations, one of the most known now is Lava Jato operation. Right before it, the Anti-Corruption law came into force, a legislative device that has as a goal to punish unlawful acts against the public administration, in which organizations will take responsibility for injuring national public or foreign administration. The law was regulated by the decree number $8.420 / 2015$, which also regulated the rules to the Leniency deal. The goal is to understand the compliance program in determination of responsibility of legal entities about the Anti-Corruption law. From bibliography research, descriptive and analytic, the article will explain a brief historical context, and the relation of compliance with the Anti-Corruption law. In this research, was observed that the Anti-Corruption law encourages companies to make some intern procedures of control. The law assures that the companies which include the Compliance program in their intern organization, even if they can't avoid unlawful acts to happen, will have a different treatment and reduced punishment. Facing this reality, this quest tried to verify how the Compliance program, will helps intern control of companies.

KEYWORDS: Compliance. Anti-Corruption Law. Responsibility. Tributary.

\section{INTRODUÇÃO}

O Brasil tem sido associado à ideia de corrupção em vários setores econômicos. Em decorrência de denúncias sobre desvio de verbas, grandes empresas tiveram sua imagem, reputação abaladas, em especial após a comprovação de seu envolvimento na prática de atos lesivo à administração pública nacional e estrangeira.

Nesse cenário, a imagem e a reputação das empresas tem se tornado relevante e mais valorizada. Nesse sentido, o Programa de Compliance vem se destacando por proporcionar a ação de condutas éticas, que estão para além do cumprimento de leis, visando também à adoção de treinamentos aos seus funcionários e contratação de profissionais preparados para detectar vícios de conduta na organização interna antes que eles se constituam como atos ilícitos que possam a corromper estrutura da instituição. A atitude preventiva busca evitar futuras responsabilizações por condutas de corrupção e as consequentes sanções. 
Após a vigência da lei anticorrupção e com a aplicação do Decreto nำ 8.420, de 18 de março de 2015, que regulamentou a lei anticorrupção, a insegurança jurídica diminuiu. $\mathrm{O}$ que trouxe notoriedade para o programa de Compliance, estando previsto nos artigos 41 e 42 do decreto.

O Decreto conjuntamente com a Lei Anticorrupção, segundo o Ministério da Transparência e Controladoria- Geral da União, incluíram a existência e aplicação de um Programa de Integridade. Logo, deverá ser considerado como um mecanismo de atenuantes no cálculo de sanções, neste caso multas administrativas previstas no art. $6^{\circ}$, inciso I, da Lei n.12.846/2013, nos termos do art. 18, inciso V, do Decreto no $8.420 / 2015$.

No que tange a lei anticorrupção, de que forma o programa de compliance pode ajudar na determinação de responsabilidade de pessoas jurídicas. Essa pesquisa esta divida em três tópicos, cujo objetivo é compreender o programa de compliance na determinação da responsabilidade jurídica e no que tange a lei anticorrupção. No primeiro tópico, é feito um breve contexto histórico, que vai trata sobre a corrupção desde o principio, a origem do compliance.

O segundo tópico irá aborda sobre a responsabilização de pessoas jurídicas com o uso do programa de compliance. Já o terceiro tópico, esta voltado para Compliance Tributário, que vai trazer a realidade das empresas, e quais são as vantagens de possuir um programa de integridade na estrutura interna da empresa. O estudo efetivado a partir da pesquisa bibliográfica, descritiva e analítica, por meio da abordagem qualitativa.

Sendo assim, o estudo propõe esclarecer como o Programa de Compliance atuará conjuntamente com Lei Anticorrupção, no caso de responsabilização de pessoas jurídicas. No qual, as empresas que não se adequarem às normas, estarão sujeitos à periculosidade.

Apesar da Lei n. 12.846/13 responsabilizar tanto a administração pública, empresas fornecedoras quantas as receptoras, e as que prestam serviços terceirizados que estejam envolvidas com atos danosos, a diminuição da ocorrência de atos de corrupção contra a administração pública ainda é um grande desafio. 


\section{BREVE HISTÓRICO DA BUSCA PELO COMBATE À CORRUPÇÃO}

O Direito Penal Econômico originou-se no século XX, após a Primeira Guerra Mundial com uma política intervencionista que teve maior evidência com a queda da Bolsa de Valores de Nova York, em 1929, ocasionando na chamada Grande Depressão, em 1930.

Assim, o Direito Econômico surgiu, aos olhos dos que testemunharam aquelas transformações em seu nascedouro, como sinônimo de transformação das estruturas do modo de produção capitalista, no sentido de afastamento de suas fundações originais. Daí ter sustentado Farjat que a mentalidade liberal do século passado representava a proibição do surgimento de um Direito Econômico. Nessa forma de visualizar o Direito Econômico, seu surgimento dataria dos anos 30 do século XX, impulsionado pelas crises que decorreram da Primeira Guerra Mundial e da quebra da Bolsa de Nova lorque (AGUILLAR, 2016, p/s.).

A partir desse período, houve o desenvolvimento do Direito Penal Econômico e a evolução na política e na economia mundial. Esse modelo de Estado incorporado ao desenvolvimento da atividade financeira e da intervenção estatal ocasionou o fenômeno conhecido como criminalidade econômica e os então chamados crimes de colarinho branco.

O termo White Collar Crime, conceituado por Edwin H. Sutherland ficou conhecido no Brasil como crimes de colarinho branco, e se refere a delitos cometidos por indivíduos de alto status social e no exercício de sua profissão, na maioria das vezes, como gestores públicos ou privados.

Os crimes econômicos mais cometidos por sujeitos que ocupam os altos postos das empresas e por políticos são: lavagem de dinheiro, violações das leis antitrustes, sonegações fiscais, obstrução da justiça, fraudes, corrupção, formação de quadrilha, conjuração entre empresas para fixar preços e dividir mercados e fraudes em obras públicas.

Além desses, são englobados pelo Direito Penal Econômico vários delitos como: crimes tributários, cartel, lavagem de dinheiro, corrupção, crimes contra o mercado de capitais e contra o sistema financeiro. 
Esses delitos são definidos em leis especiais, tais como a Lei ํo 7492/86 Crimes contra o Sistema Financeiro Nacional; a Lei no 8137/90 - Crimes contra a Ordem Tributária e a Lei no 9613/98 - Lei de Lavagem de Dinheiro.

O Brasil com a promulgação da Constituição da República Federativa do Brasil seguiu a tendência dos vários países ao abraçar normas regulamentadoras da ordem econômica. É importante lembrar que o governo de Fernando Collor, o primeiro presidente eleito diretamente, após o fim da ditadura, foi envolvido em caso de corrupção que envolvia um esquema de caixa dois e vendas superfaturadas o que comprometeu a sua permanência no cargo.

Em seguida, no governo de Itamar Franco foi colocada em prática a lei $n^{\circ}$ 8.666/92, Lei de Licitações que foi uma das leis mais importante no combate à corrupção no Brasil (HERNANDES,2011).

Durante o governo de Fernando Henrique Cardoso foi aprovada a Lei Complementar №. 101, ou Lei de Responsabilidade Fiscal que representava um grande avanço no país, pois colaborou aumentando a transparência dos gastos públicos em todas as esferas governamentais. Mesmo com esse avanço houve uma série de denúncias de corrupção no governo de FHC (HERNANDES, 2011).

Ainda no fim do governo FHC, foi criada a então Corregedoria-Geral da União depois, em 2003, denominada Controladoria-Geral da União (CGU), órgão incumbido de assistir o presidente da Republica nos seguintes assuntos: defesa do patrimônio público, controle interno, auditoria pública, correição, prevenção à corrupção, atividades de ouvidoria e incremento da transparência. (HERNANDES, 2011, p.23).

Em 2003, com a criação da Controladoria-Geral da União, medidas importantes foram adotadas na prevenção à corrupção, como a promoção da CGU ao status de ministério, posteriormente, houve aprovação da Lei Complementar №. 135, chamada de Lei da Ficha Limpa. Já o ano de 2005 foi marcado pelo escândalo de corrupção no governo de Lula que ficou conhecido como Mensalão. Um dos casos de corrupção que teve grande notoriedade no país (HERNANDES, 2011).

Em 2013, foi promulgada a Lei Anticorrupção mais uma medida de combate à corrupção conjuntamente com a figura do Compliance e no ano seguinte aconteceu o mais recente caso de corrupção de grande repercussão que ocorreu durante o governo 
de Dilma Rousseff, que ficou conhecido a partir da operação investigativa deflagrada pela Polícia Federal, a Operação Lava Jato.

\subsection{A origem do Compliance}

O Compliance surgiu nos Estados Unidos por volta do século XX, com o objetivo de regulamentar as atividades que envolviam a saúde alimentar e o comércio de medicamentos, e para combater a corrupção de organizações americanas no exterior. Para isso, houve a implementação de penas mais severas quando os crimes fossem praticados contra a administração pública.

Com o aumento dos escândalos de corrupção mundialmente, principalmente, envolvendo empresas privadas e o próprio governo, algumas empresas começaram a adotar medidas, que atualmente, são reconhecidas como Compliance. O compliance é um programa de integridade que tem com objetivo prevenir e proteger, as empresas de atos lesivos, como a corrupção.

O Brasil, diante das inovações legislativas e da propagação dos escândalos procurou se adequar à política de combate à corrupção, buscando o aprimoramento de mecanismos que possibilitem a detecção de atos lesivos contra a administração pública e assim permite puni-los, conforme disposto nas legislações.

Nesse contexto, aparecem alguns exemplos marcantes: a Lei de Improbidade Administrativa (Lei 8.429/92), a Lei Geral de Licitações e Contratos (Lei 8.666/93), a Lei de acesso à informação (Lei 12.527/2011), a criminalização da corrupção internacional no Código Penal e a aprovação da Lei Anticorrupção (Lei 12.846/2013). As duas últimas são desdobramentos diretos da assinatura pelo Brasil da "Convenção sobre o Combate à Corrupção de Funcionários Públicos Estrangeiros em Transações Comerciais Internacionais" da OCDE (MENDES; MARQUES, 2017, p. 22 - 23).

Com essas leis, houve um crescimento nas operações que investigam e apuram os atos ilícitos contra a administração pública, sendo cada vez mais difícil os infratores saírem impunes. A lei considerada como responsável por introduzir o programa de Compliance no Brasil e no ordenamento jurídico foi a Lei de Lavagem de Dinheiro. 
Neste sentido, leciona que em virtude de o presente tema ser relativamente novo, muitas vezes é analisado e subsumido a discussões próprias do Direito Penal Econômico, como por exemplo, sobre a posição de garantidor do responsável pelo Compliance, questões inerentes à responsabilidade do administrador da empresa, dentre outras (ROTSCH apud GUEDES, 2012, p. 3).

É importante ressaltar que o Compliance conseguiu grande notoriedade no Brasil, em razão da Operação Lava Jato, considerada como marco inicial para o desencadeamento de outras investigações, sendo marcada por escândalos internacionais e principalmente nacional.

Deflagrada oficialmente em 17 de março de 2014, a operação Lava Jato envolve inúmeros crimes, como corrupção de agentes do governo, fraudes em licitações, contrabando, fraudes fiscais e desvios de dinheiro público, resultando em um escândalo que abrange figuras políticas em diversos níveis do governo e grandes empresas públicas e privadas (MENDES; MARQUES 2017, p.24).

Em decorrência dos escândalos da Operação Lava Jato, em 2014, as empresas começaram a investir em Compliance.

Dessa forma, o programa de Compliance pode ser uma ferramenta na prevenção de lavagem de dinheiro. Com afirma Coimbra (2016), o âmbito de sua abrangência, o programa é voltado às áreas com maior risco de crises institucionais e de imagem, ou cuja regulação exija a criação de um setor. A Lei de Lavagem de Dinheiro, passou a exigir de determinadas empresas e profissionais que adotem "políticas, procedimentos e controles internos" que Ihe permitam atender as obrigações elencadas no art.10, tornando assim obrigatório o desenvolvimento e implementação de programas de Compliance.

No ano anterior, em 2013, foi aprovada pelo Congresso Nacional a Lei oㅡ 12.846/2013, conhecida como Lei de Anticorrupção que também contribuiu para uma significativa revolução no cenário brasileiro, conjuntamente com o programa de Compliance.

Como afirma Mendes (2017), a Lei Anticorrupção extrapola qualquer debate político-jurídico, em razão dos seus efeitos reais e perceptíveis, mesmo que o programa de Compliance seja anterior, foi em razão da Lei Anticorrupção que o mesmo ganhou um novo significado e alcançou diversas áreas, fazendo com que passasse a ser objeto de preocupação. 
A Lei Anticorrupção foi apenas o ponto inicial, logo após outras normas vieram, como o Decreto n. 8.420/15, que possui como objetivo principal regulamentar a Lei Anticorrupção em face do Compliance e combater a corrupção prevendo quais são as autoridades competentes para investigar e punir os crimes que ofendam o patrimônio público.

\begin{abstract}
Inicialmente tratadas, no Brasil, dentro da realidade da Lei de Lavagem de Dinheiro original (Lei n. 9.613, de 3-3-1998), as noções de criminal Compliance passaram por profunda alteração, em especial após a entrada em vigor da Lei n. 12.683, de 9-7-2012, a qual reestruturou toda a dinâmica relativa ao tratamento penal da lavagem de capitais. Em momento posterior, existiu uma reviravolta em relação ao criminal Compliance, em especial com a Lei $n$. 12.846, de 10-8-2013, que dispõe sobre a responsabilização administrativa e civil de pessoas jurídicas pela prática de atos contra a administração pública, nacional ou estrangeira (MELLO, 2017, p.27).
\end{abstract}

Ademais, houve avanços nos procedimentos de investigação e as punições aumentaram em decorrência da onda de combate a corrupção no Brasil. O governo buscou estabelecer comunicação entre a defesa da concorrência e o combate à corrupção e dedicou-se, continuamente, à "elaboração e aprimoramento legislativo para ampliar os mecanismos de detecção e punição de atos lesivos praticados contra o patrimônio público" (MENDES; MARQUES, 2017, p. 22).

Logo, os mecanismos contra a corrupção e as políticas de combate à prática de atos lesivos, vem ganhando mais espaço no cenário brasileiro, o que promove mudanças nas estruturas política-judiciária, havendo assim uma cooperação entre as autoridades competentes nas investigações, como ocorre entre 0 Conselho Administrativo de Defesa Econômica - CADE e o Ministério Público Federal (MPF).

\title{
1.2 Conceito de Compliance
}

O termo Compliance vem do verbo em inglês to comply, que significa agir de acordo com uma regra, ou seja, está em conformidade com as leis e regulamentos nacionais e internacionais.

Conforme Badaró e Bottini (2016, p.52), "significa o ato voltado ao cumprimento das normas reguladoras de determinado setor", ou seja, significa o aumento da transparência das organizações aprimorando seus valores e princípios, e não se 
preocupando apenas com o cumprimento das normas, mas com a ética das empresas ajudando-as no desempenho em relação às sociedades e protegendo os futuros investidores.

\begin{abstract}
Nessa mesma perspectiva, surgiu a necessidade de tornar as organizações cada vez mais íntegras e capazes de se resguardar das constantes guinadas cíclicas do mercado, possibilitando, assim, a criação e o aprimoramento do que, no âmbito institucional e corporativo, é conhecido como Compliance. (SILVA; COVAC, 2015, p.2).
\end{abstract}

Como o passar do tempo, o termo foi ampliado para se adequar ao mundo corporativo e transformado num conjunto de disciplinas e práticas que visam ao cumprimento de normas de uma instituição, procurando investigar, evitar e solucionar qualquer desvio, risco ou inconformidade nas empresas.

A partir disso, ocorreu o desencadeamento do Compliance com 0 desenvolvimento de documentos, leis que obrigam a instalação desse programa e a assinatura de acordos, como por exemplo, a Convenção Interamericana contra a Corrupção, a Convenção sobre o Combate à Corrupção de Funcionários Públicos Estrangeiros em Transações Comerciais Internacionais - OCDE, a política intervencionista denominada New Deal, e a Conferência de Bretton Woods, em 1944.

Pode ser considerada, como atividade recente no âmbito jurídico, pois somente solidificou-se após os mundialmente famosos escândalos de governança (Barings, Enron, World Com, Parmalat) e a crise financeira de 2008 (COIMBRA apud BADARÓ, 2016, p. 53).

A Convenção das Nações Unidas, aprovada em 2003, pela Organização das Nações Unidas - ONU é considerada a primeira convenção que contou com o apoio da Alemanha, França, Japão e Reino Unido ao combate à corrupção. Visando o efetivo cumprimento das normas e a devida investigação no cenário corporativo e a busca por evitar ou solucionar casos de desvio ou inadequação, a Convenção é considerada o instrumento de maior eficácia no combate a corrupção em nível internacional.

Diversos países signatários dessas convenções mudaram sua legislação para que houvesse colaboração internacional entre o que era proposto e a aplicação 
das punições contra os atos lesivos, como por exemplo, "nos Estados Unidos, a intensificação do combate à corrupção é bastante perceptível, como se verifica no aumento de ações realizadas com base no Foreign Corrupt Practices Act (FCPA)" - no início do século XXI.1 (MENDES; MARQUES, 2017, p.13).

$[\ldots]$

Como ocorreu com o combate à corrupção, a política de defesa da concorrência se tornou uma questão global de grande relevância, o que exige uma mudança de postura não apenas das autoridades regulatórias, mas também das empresas, para se adequarem às regras da defesa da concorrência (MENDES; MARQUES, 2017, p.21).

Diante desse contexto de relação econômica, foi criada a Lei no 8.884/94 chamada de Lei de Defesa da Concorrência, que foi alterada pela Lei oㅡ 12.529/2011, no qual visa à fiscalização e punição de crimes contra a ordem econômica, sendo aplicada por meio do Conselho Administrativo de Defesa Econômica (CADE).

O Conselho Administrativo de Defesa Econômica surgiu como parte integrante de uma rede de autoridade concebidas para a defesa da concorrência no mundo, bem como para o combate à corrupção. Essa rede alcançou uma proporção global ocasionando modificações em diversas empresas e acarretando mudanças de postura de autoridades e empresas que se ajustaram à defesa da concorrência e da ética.

A definição de Programa de Integridade encontra-se no artigo 41 do Decreto №. $8.420 / 2015$.

Art. 41 Programa de Integridade consiste, no âmbito de uma pessoa jurídica, no conjunto de mecanismos e procedimentos internos de integridade, auditoria e incentivo à denúncia de irregularidades e na aplicação efetiva de códigos de ética e de conduta, políticas e diretrizes com objetivo de detectar e sanar desvios, fraudes, irregularidades e atos ilícitos praticados contra a administração pública, nacional ou estrangeira. (BRASIL, 2015).

O programa de integridade atua na prevenção e no combater a corrupção. Esse programa definido pelo Decreto ำ. 8.420/2015 é chamado de Compliance e vem desempenhando atividades em diferentes setores econômicos. Logo ele possuir uma abrangência enorme, não se limitando a um modelo específico se adequando às condições e necessidades da empresa.

\subsection{Modelos de Compliance}

O Compliance, como um programa de integridade, visa à prevenção e à prevenção de atos ilícitos nas corporações, sejam pequenas ou grandes empresas de diversas aéreas econômicas e abrange vários de seus setores. 
Dessa forma, não se pode falar em um modelo específico de Compliance que todas as empresas deverão adotar, uma vez que ele será incorporado nos negócios da empresa levando em consideração as particularidades que cada empresa possui. Portanto, o programa de Compliance será elaborado pela própria empresa, que analisará e estabelecerá quais mecanismos se amoldam à sua estrutura.

Entretanto, as empresas não possuem total liberdade já que o sistema para detectar condutas irregulares terá que ser conforme as normas instituídas pelo Estado, por meio de leis, como a Lei de Anticorrupção que foi regulamentada pelo Decreto oㅜ 8.420/2015 que traz em seu artigo 42.

Art. 42. Para fins do disposto no $\S 40$ do art. 5o, o programa de integridade será avaliado, quanto a sua existência e aplicação, de acordo com os seguintes parâmetros:

I - comprometimento da alta direção da pessoa jurídica, incluídos os conselhos, evidenciado pelo apoio visível e inequívoco ao programa;

II - padrões de conduta, código de ética, políticas e procedimentos de integridade, aplicáveis a todos os empregados e administradores, independentemente de cargo ou função exercidos;

III - padrões de conduta, código de ética e políticas de integridade estendidas, quando necessário, a terceiros, tais como, fornecedores, prestadores de serviço, agentes intermediários e associados;

IV - treinamentos periódicos sobre o programa de integridade;

V - análise periódica de riscos para realizar adaptações necessárias ao programa de integridade;

$\mathrm{VI}$ - registros contábeis que reflitam de forma completa e precisa as transações da pessoa jurídica;

VII - controles internos que assegurem a pronta elaboração e confiabilidade de relatórios e demonstrações financeiros da pessoa jurídica;

VIII - procedimentos específicos para prevenir fraudes e ilícitos no âmbito de processos licitatórios, na execução de contratos administrativos ou em qualquer interação com o setor público, ainda que intermediada por terceiros, tal como pagamento de tributos, sujeição a fiscalizações, ou obtenção de autorizações, licenças, permissões e certidões;

IX - independência, estrutura e autoridade da instância interna responsável pela aplicação do programa de integridade e fiscalização de seu cumprimento;

$X$ - canais de denúncia de irregularidades, abertos e amplamente divulgados a funcionários e terceiros, e de mecanismos destinados à proteção de denunciantes de boa-fé;

$\mathrm{XI}$ - medidas disciplinares em caso de violação do programa de integridade;

XII - procedimentos que assegurem a pronta interrupção de irregularidades ou infrações detectadas e a tempestiva remediação dos danos gerados;

XIII - diligências apropriadas para contratação e, conforme o caso, supervisão, de terceiros, tais como, fornecedores, prestadores de serviço, agentes intermediários e associados;

XIV - verificação, durante os processos de fusões, aquisições e reestruturações societárias, do cometimento de irregularidades ou ilícitos ou da existência de vulnerabilidades nas pessoas jurídicas envolvidas; 
XV - monitoramento contínuo do programa de integridade visando seu aperfeiçoamento na prevenção, detecção e combate à ocorrência dos atos lesivos previstos no art. 50 da Lei no 12.846, de 2013; e

XVI - transparência da pessoa jurídica quanto a doações para candidatos e partidos políticos. (BRASIL, 2015).

Há muitas discussões em torno da estruturação do Compliance e a dúvida é se existe um modelo ideal, ou não. O modelo de Compliance dependerá da evolução da empresa, ele evolui através das crises. As crises fazem com que haja necessidade de identificar falhas para serem corrigidas.

Questionando-se sobre qual é o modelo ideal, será identificado que o resultado obtido é o que interessa, não importando o modelo que foi utilizado. Portanto não existe um modelo de Compliance perfeito. Outro elemento importante a ser analisado para efetivação do Compliance na corporação é o que ela que almeja atingir no momento. Qual é a realidade da empresa, e quais são suas necessidades em relação à adoção do programa de integridade.

\section{RESPONSABILIDADE DE PESSOAS JURÍDICA NO COMPLIANCE}

O Brasil, por ser signatário da Convenção Interamericana contra a Corrupção, realizou algumas mudanças na legislação para atender às medidas exigidas pelo tratado. Por essa razão, em 2012, entrou em vigor no Brasil a Lei n. 12.683/2012 que alterou a Lei n. 9.613/1998 - Lei de Lavagem de Capitais, introduzindo o programa de Compliance, considerado como fruto de combinações normativas, daí por que, suas consequências também necessariamente são penais, com reflexos possíveis na figura do empresário.

No particular caso da Lei Anticorrupção, sua estruturação dependerá de uma avaliação de verdadeira profusão normativa, afastando-se as contradições, sobretudo em relação às Leis de Improbidade Administrativa (Lei n. 8.429, de 2-7-1992); de Licitações Públicas (Lei n. 8.666, de 21- 6-1993); de Concorrência (Lei n. 12.529, de 30 11-2011) e à nova Lei de Lavagem de Dinheiro (Lei n. 12.683, de 9-7-2012), além das inúmeras outras normativas administrativas aplicáveis (MELLO, 2017, p.322).

No âmbito jurídico, antes da aprovação da Lei de Anticorrupção, a única norma que tratava sobre corrupção era o Código Penal que responsabilizava apenas as 
pessoas físicas, não atingindo em nenhuma hipótese as pessoas jurídicas. Após a assinatura da Convenção Interamericana, Convenção das Nações Unidas e da Organização para a Cooperação e Desenvolvimento Econômico, conhecida pela sigla OCDE, o Brasil buscou atender as propostas realizadas pelos organismos internacionais.

[...] criminalizou 0 ato de corrupção de funcionário público estrangeiro com a promulgação da Lei n. 10.467, de 11 de junho de 2002, que acrescentou, ao Código Penal, a Seção XI, com o Capítulo II-A sob o título "Crimes praticados por particular contra a administração pública estrangeira", que contempla o crime de corrupção ativa em uma transação comercial internacional e a definição de "funcionário público estrangeiro" (SANTOS, 2013, p.20).

$[\ldots]$

Para avaliar os resultados desenvolvidos pelo governo no combate à corrupção e verificar os avanços alcançados com a mudança na legislação, alguns representantes da OCDE vieram para o Brasil, e publicaram e 2014 um relatório afirmando que o país havia evoluído positivamente, inclusive após a Lei no 12.846/2013, que pôs fim há anos de inconformidade com a Convenção (SANTOS, 2013, p. 22).

O Brasil respeitando o tratado adotou o Compliance como um mecanismo de transparência, proteção e prevenção de atividades ilícitas internas e externas, buscando facilitar tanto a detecção de infrações penais quanto a atuação das autoridades na apuração da responsabilização penal do indivíduo, visando novas formas de prevenir a responsabilidade jurídica da instituição e regulamentar as ações que colaboram com a eficácia de boas práticas no cumprimento das normas atuantes nas empresas.

Conforme Badaró e Bottini (2016), o Compliance pode ser caracterizado como um instrumento de resiliência da empresa, transformando as falhas que forem detectadas em aprimorando dos seus procedimentos internos de controle.

Ainda de acordo com o autor, o objetivo central das políticas de Compliance é assegurar o devido cumprimento das normas instituídas por empresas ou setores, a fim de evitar futuros problemas jurídicos, administrativos, de imagens e reputação, em casos de conflitos internos ou externos com os atos regulatórios.

Atualmente, é possível perceber a tendência de pessoas (físicas e jurídicas) a utilizar a ética como paradigma necessário para a contratação de uma empresa ou para a compra de produtos. Também é possível registrar o movimento de pessoas dispostas a rescindir contratos ou deixar de consumir (produtos ou 
serviços) de empresas claramente envolvidas em atos escusos ou contrários à moral e à ética mínima esperada (SILVA; COVAC, 2015, p.7).

Consequentemente, com a implementação deste programa, existe a possibilidade de exclusão da responsabilidade de pessoas jurídicas, ou seja, as empresas ganham um tratamento diferenciado daqueles que não investiram na prevenção e proteção de suas empresas.

A ideia de risco é central para o tema do Compliance. É frequente a assertiva de que os programas de Compliance são voltados à prevenção de delitos cometidos no seio das empresas. Ao mesmo tempo, o Compliance é uma estratégia utilizada para minimizar os riscos reputacionais e legais aos quais a empresa está sujeita, caso ocorram práticas de corrupção e/ou lavagem de dinheiro. Para mitigar os riscos, a estratégia é a prevenção (VERRíSSIMO, 2017, p.104).

Portanto, quando uma instituição está em conformidade (Compliance), ela dissemina a ética, mitiga riscos, age com transparência, monitora seus colaboradores e clientes, e comunica as faltas de conformidade às autoridades competentes, contribuindo para o bom funcionamento do sistema e evitando sua utilização em fraudes ou outras inconformidades (SILVA; COVAC, 2015, p.8).

Desta forma, uma das características marcantes do Compliance é a ética, sendo cada vez mais inserida no ambiente empresarial para combater as condutas imorais e resguardar a integridade corporativa. No entanto, o Compliance vai além das condutas éticas, assumindo também o controle sobre as atividades empresariais e evitando perda financeira e/ou da sua reputação.

\subsection{Instrumentos de Compliance}

Os instrumentos de Compliance estão elencados no artigo 42 do Decreto no 8.420/2015. Esses instrumentos permitem a cumprimento das funções do Compliance. Tornando assim mais eficaz o seu desempenho e reforçando seus mecanismos. São exemplos de instrumentos: canal de ouvidoria, educação e treinamento, gestor, medidas corretivas, observatório de Compliance, políticas e procedimentos e sistema de monitoramento. 


\subsubsection{A Lei Anticorrupção como um possível instrumento para o Compliance}

Corrupção é o ato de corromper algo ou alguém, com o objetivo de obter vantagem, oferecer dinheiro ou presente em troca de vantagens, de interesse pessoal. Para que haja a corrupção, são necessários no mínimo dois indivíduos: o corruptor e o corrompido.

Existem seis tipos diferentes de corrupção, sendo corrupção intencional, necessária, ativa, passiva, preditiva e lateral. No Brasil, a corrupção pode ser percebida desde o século XVI, período da colonização portuguesa e o seu primeiro registro foi produzido pelo escrivão de Pedro Álvares Cabral.

Pero Vaz de Caminha escreveu uma carta contando sobre a terra descoberta e aproveita para pedir vantagens ao rei de Portugal. Em um trecho da carta, Pero Vaz de Caminha que solicita ao rei que libertasse seu genro.

"E pois que, Senhor, é certo que tanto neste cargo que levo como em outra qualquer coisa que de Vosso serviço for, Vossa Alteza há de ser de mim muito bem servida, a Ela peço que, mande vir a ilha de São Tomé a Jorge Osório, meu genro..." (MEDEIROS, ROCHA, 2016, p.7).

Nos primeiros anos após o descobrimento do Brasil, a fraude mais comum na colônia era o contrabando do ouro, sendo uma das formas de se fazer corrupção por meio dos santos de madeira vazios na parte interna, onde eram escondidas pedras preciosas (MEDEIROS, ROCHA, 2016).

Além disso, há relatos históricos de que funcionários públicos do rei contrabandeavam mercadorias, recebendo propinas para desviarem produtos, ao invés de cumprirem suas funções.

A corrupção é percebida, ainda no período de escravidão com o comércio de escravos para trabalharem nas lavouras. Era comum os donos de fazendas arrumarem uma forma de burlar a lei de tráfico e vender escravos mais baratos. A coroa portuguesa não tomava atitudes para acabar com a escravidão, além disso, cobrava propinas para fingir que nada estava acontecendo. Com a Proclamação da Independência do Brasil em 1922, apareceram outras formas de corrupção, como a corrupção eleitoral. 
A corrupção eleitoral, com a compra e venda de votos é também o conhecido voto de "cabresto" em que os funcionários analfabetos eram forçados a votarem conforme o desejo do patrão. Logo, vieram as concessões de obras públicas superfaturadas, desvio de dinheiro por parte de políticos, ou seja, as práticas que presenciamos atualmente na política, já aconteciam desde século 16.

A ditadura militar foi também marcada pela corrupção oculta, no qual havia uma promessa de combate à corrupção, mas o que ocorreu foi a censura quanto á publicidade da ocorrência dos atos ilícitos. Somente com a promulgação da Constituição Federal em 1998, que o país passou a falar e se preocupar mais com a corrupção.

A população começou a viver um período de maior participação na política, como a escolha dos representantes legislativos e executivo. No entanto, os casos de corrupção que recentemente mais ficaram conhecidos no Brasil foram: o Mensalão do Tucano (2005), o Mensalão do PT (2006), a Máfia dos Sanguessugas (2009), Mensalão do DEM, e a mais recente, Operação Lava Jato (2014).

O fortalecimento do combate à corrupção e a cartéis, em um círculo virtuoso, levou a novas iniciativas do governo para conferir relevância ao tema - entre elas, destaca-se o Decreto n. 8.420/2015, que veio regulamentar a Lei Anticorrupção e, em matéria de Compliance, trouxe parâmetros bastante detalhados sobre como tais programas serão avaliados pela Administração (MENDES; MARQUES, 2017, p.29).

O Compliance tem suma importância no cenário corporativo podendo ser utilizado nas instituições públicas e privadas, portanto, quando uma empresa deixa de utilizar o programa de Compliance, está correndo o risco de manchar sua imagem perante toda a sociedade e dos futuros investidores, causando assim uma grande perda financeira. Além da reputação manchada e abalada, poderá ainda responder a sanções perante os órgãos reguladores.

A Lei Anticorrupção tratará da responsabilidade objetiva administrativa de pessoas jurídicas pela prática de atos lesivos contra a administração pública, e serão atribuídas responsabilidades penais às pessoas físicas que não cumprirem os deveres intrínsecos da empresa, como os dirigentes que no seu dever de vigilância acabaram deixando acontecer condutas ilícitas de seus subordinados. O Compliance tem o papel 
de restrição das responsabilidades, não mais abrangendo, todo o Conselho de Administração de uma dada empresa, mas apenas aquele ou aqueles que assumam o papel de garantidor (SILVEIRA, 2015).

Imagine-se a dificuldade de verificação de responsabilidades em um ambiente onde os chefes hierárquicos dão ordens a gerentes intermediários que por sua vez dão comandos à base da estrutura piramidal de poder, que, por sua vez, executa determinado ato delitivo (SILVEIRA, 2015, p. 129).

O chefe hierárquico tem o papel de garantidor dentro da estrutura interna da empresa, assumindo a responsabilidade pelos fatos que ocorrerem naquele ambiente em sua gestão e que não foram evitados. Por conseguinte, ressalta Silveira (2015, p. 131) "evidentemente, não se espera, com isso, que o empresário assuma a obrigação de evitar toda e qualquer inocorrência criminosa na empresa, mas apenas, o que se entende por delitos vinculados ao estabelecimento". Sendo assim, nos casos em que o agente devia e/ou poderia agir para evitar a conduta lesiva e não fez, ou se a empresa não constituiu em seu bojo um programa de Compliance ou se o programa é defeituoso deixando brechas para a prática de ilícitos, ficará evidenciada a omissão na conduta do empresário que será, consequentemente, responsabilizado pelos atos.

Nos Estados Unidos, por exemplo, três foram os fatores que possibilitaram a expansão da responsabilidade criminal às corporações e entidades: 1) a progressiva aplicação, pelas cortes, da responsabilidade criminal a empresas, por danos causados concretamente; 2 ) o desenvolvimento da responsabilidade criminal por ato de outrem (vicarious liabilitv); 3) a evolução do requisito da intenção criminosa, ou mens real (VERRÍSIMO, 2017, p. 32).

As empresas responderam de acordo com o sistema adotado por cada país, o Código dos Estados Unidos iguala à pessoa jurídica a pessoa física, enquanto o Brasil responsabiliza administrativamente e civilmente, com exceção há alguns casos em que poderão responder criminalmente ou então apenas as pessoas físicas serão responsabilizadas.

Segundo a Controladoria-Geral da União, para que uma pessoa jurídica seja responsabilizada no âmbito da Lei no 12.846/2013, considerando o devido processo legal, é necessário comprovar, o cometimento de um ou mais dos atos lesivos previstos no art. $5^{\circ}$, da referida lei, sendo que a comprovação de que a prática de tal ato lesivo pela pessoa jurídica foi em seu interesse ou benefício, exclusivo ou não. Ou 
seja, para que a pessoa jurídica seja responsabilizada é preciso a comprovação, por exemplo de desvio de verbas, e que constitua ocorrência fática do ato ilícito, em razão de algum interesse ou benefício a empresa. Como afirma a Controladoria Geral da União (2018) a responsabilização é mais que objetiva, pois independe de uma responsabilização anterior ou posterior da pessoa física, seja o representante ou o preposto da pessoa jurídica.

Esta realidade de organização judicial e econômica está sujeita a multas pecuniárias sublimes, punições administrativas e penas de prisão aos dirigentes. A Lei Anticorrupção prevê, em seu artigo 6으, a aplicação de sanção administrativa com multa de $0,1 \%$ (um décimo por cento) podendo chegar a $20 \%$ (vinte por cento), o que acarretará em prejuízo pecuniário para a empresa, servindo assim, de incentivo para que não haja mais ocorrência de atos ilícitos no ambiente organizacional. Ainda que haja a aplicação de sanção administrativa, a pessoa jurídica não ficara isenta de reparar os danos causados à Administração Pública.

\subsubsection{Acordo de Leniência}

O acordo de leniência foi chamado de colaboração premiada até o final do século XX, pois em decorrência da Lei no 8.072/1990, a Lei de Crimes Hediondos, o ordenamento jurídico passou a adotar a nomenclatura delação premiada, consequentemente, considerado como acordo de leniência.

$O$ acordo de leniência foi observado desde o século $X X$, mas apenas ganhou notoriedade no século XXI, sendo previsto pela Lei de Anticorrupção que visa estabelecer acordos entre as empresas, para que haja colaboração na investigação de delitos contra os bens públicos, trazendo muitos benefícios tanto para o seguimento das investigações, como para as empresas, que poderão se isenta de determinadas penalidades.

O art. 17, da Lei Anticorrupção, vai mais longe e destaca que "a Administração Pública poderá também celebrar acordo de leniência com a pessoa jurídica responsável pela prática de ilícitos previstos na Lei $n$. 8.666, de 21 de junho de 1993, com vistas à isenção ou atenuação das sanções administrativas estabelecidas em seus arts. 86 a 88. "Afirma-se, em outras palavras, que o órgão da Administração Pública pode celebrar acordo de leniência com vistas a simples isenção de responsabilidades. Não se fala de isenção de sanções 
penais, mas a situação aqui tem clara proximidade com as menções penais feitas na Lei Antitruste brasileira (MELLO, 2017, p.344).

A Lei Anticorrupção em busca da responsabilização de pessoas jurídicas envolvidas com algum ato ilícito determina a possibilidade de acordos entre empresas que pertençam ao mesmo grupo econômico e prevê benefícios ao delator que será uma pessoa jurídica dotada de capacidade para assumir tal responsabilidade. A lei, no entanto, não estabelece em seu conteúdo o que poderia ser considerado como grupo econômico de fato e de direito, por conseguinte, subentende-se que grupo econômico seria, a junção de várias pessoas jurídicas, com um determinado interesse em comum. Essas pessoas jurídicas terão acordos iguais que se beneficiaram dele, desta forma amenizando as repercussões que surgirem negativamente.

Um acordo de leniência assinado no âmbito da Lei Anticorrupção, portanto, não irá necessariamente acarretar benefícios ou imunidades ao agente privado com relação a ilícitos previstos em outras leis. Tendo em vista que o acordo de leniência exige a confissão da participação no ilícito, ele pode, inclusive, servir de fundamento para a propositura de ações judiciais de responsabilização por outras autoridades (MENDES; MARQUES, 2017, p.112).

Portanto, a Lei Anticorrupção concedendo autoridade máxima aos órgãos que possuem competência para celebrar os acordos de leniência, entre pessoas jurídicas que estejam envolvidas com atos ilícitos contra a administração pública. Pestana (2016, p. 172), afirma que, "segundo ainda o decreto federal, poderá ser firmado memorando de entendimentos entre a pessoa jurídica proponente e a Controladoria-Geral da União para formalizar a proposta e definir os parâmetros do acordo de leniência". Por conseguinte, a Controladoria-Geral da União- CGU, será o órgão competente para realizar os acordos de leniência e o Ministro de Estado Chefe da Controladoria-Geral da União que ficará encarregado de celebrar os ajustes necessários.

A formalização do acordo deve obedecer a condições específicas cumuladas com a Lei Anticorrupção, sendo que a primeira condição que a lei estabelece é que haja interesse por parte da pessoa jurídica, logo esta deverá procurar manifestar seu interesse em cooperar. Outro quesito é manter o sigilo até a sua formalização, o que significa que a pessoa jurídica está disposta a colaborar. O terceiro é assumir que tenha praticado o ato lesivo contra a administração pública nacional ou estrangeira. O quarto é cooperar com as investigações e o processo administrativo. E o último requisito é 
respeitar o período no qual o acordo de leniência possa ser validado, proposto e formalizado.

O Decreto n. $60.106 / 2014$, no seu art. 4o, § 2o, determina que a proposta de acordo de leniência deverá ser encaminhada à autoridade competente, por escrito, em envelope lacrado e claramente identificado com os termos "Proposta de acordo de leniência" e "Confidencial" (PESTANA, 2016, p.164).

O Decreto Federal 8.420/2015, que regula a Lei de Anticorrupção, ressalta a respeito do acordo, que deverá ser cumprido no prazo de 180 dias. Caso o colaborador descumpra o acordo de leniência, perderá seus benefícios, ficando impedido de formalizar novo acordo no prazo de 03 anos contados do conhecimento, pela Administração Pública, do referido descumprimento. O descumprimento do acordo de leniência pode se dar no período entre a celebração do ajuste e o término do processo.

Até o momento, o Ministério da Transparência (CGU), em conjunto com a Advocacia-Geral da União (AGU), assinou cinco acordos de leniência com empresas investigadas pela prática dos atos lesivos previstos na Lei Anticorrupção (no 12.846/2013) e dos ilícitos administrativos previstos na Lei de Licitações ( $n^{\circ}$ 8.666/1993).

Os valores a serem ressarcidos envolvem os pagamentos de multa, dano e enriquecimento ilícito. Outros 13 acordos de leniência estão em andamento, com previsão de que pelo menos cinco deles sejam concluídos até o final de 2018. O retorno estimado de recursos aos cofres públicos é de aproximadamente $\mathbf{R} \mathbf{\$} 10$ bilhões (MINISTÉRIO DA TRANSPARÊNCIA, 2018, $\mathrm{s} / \mathrm{p}$, grifo do autor).

Os benefícios decorrentes da formulação do acordo de leniência e da colaboração por parte das pessoas jurídica serão isenção da publicação extraordinária da decisão administrativa sancionadora; isenção da proibição de receber incentivos, subsídios, subvenções, doações ou empréstimos de órgãos ou entidades públicos e de instituições financeiras públicas ou controladas pelo Poder Público; redução, em até 2/3 (dois terços), do valor final da multa aplicável e isenção ou atenuação das sanções administrativas previstas nos diplomas legais.

De acordo com o Cade, em 2001 instaurou inquérito Administrativo para investigar suposto cartel em concorrências públicas realizadas pela Petrobras. 0 inquérito e mais incremento da Operação Lava Jato foi realizado a celebração de acordo de leniência. Por meio da Leniência, assinada pelo Cade em conjunto com o Ministério Público Federal. As empresas e pessoas físicas confessaram sua participação e apresentaram documentos a fim de colaborar com as investigações. Ao 
todo já foram realizados pelo Cade seis acordos de leniência no âmbito da "Operação Lava Jato".

\section{COMPLIANCE TRIBUTÁRIO}

As empresas no desenvolvimento de suas atividades praticam fatos geradores de vários tributos e para mantê-los em dias é necessário um planejamento tributário para que os pagamentos de impostos e contribuições sejam realizados de forma correta para que não haja preocupações futuras. Neste contexto, o Compliance tributário surge para atuar na revisão e na análise das informações que serão entregues ao Fisco, no controle do pagamento evitando que o mesmo tributo seja pago duas vezes ou que seja pago a menos ou a mais do que devia e para que o mesmo seja satisfeito na data prevista.

O Fisco controlará e fiscalizará o cumprimento da norma tributária em todas as esferas de sua competência. Com a adoção do Compliance tributário, os dados declarados ao Fisco digitalmente terão mais qualidade e conformidade com a legislação, portanto, a empresa não terá preocupações com problemas futuros, como multas, sanções, prejuízos nos rendimentos e até mesmo uma execução fiscal.

Tendo em vista que há constantes mudanças nas normas e a grande dificuldade para acompanhar essas mudanças realizadas tanto pela União como pelos Estados, Distrito Federal e Municípios, o poder legislativo buscou uma forma de integrar e compartilhar entre esses entes informações fiscais.

Para iniciar a padronização entre as várias esferas de Governo, foi publica a Emenda Constitucional no 42, de 19 de dezembro de 2003, introduzindo o inciso XXII ao art. 37 à Constituição Federal de 1998 que as administrações tributárias da União, Estados, Distrito Federal e Municípios devem atuar de forma integrada, compartilhando cadastros e informações fiscais. (MARIANO; PERES, 2012, p.27).

Dessa forma, com o amparo da Emenda Constitucional no 42/2003 e com a modernização da Receita Federal é possível que a mesma tenha acesso às informações de todas as movimentações que são feitas nas empresas de forma digital, por isso a importância da adoção do Compliance tributário. Já que outrora para que a empresa fosse avaliada era preciso o deslocamento do Fisco para realizar a 
fiscalização pessoalmente, o que não é mais necessário em razão do cruzamento de dados de forma digital.

Este cruzamento de dados é feito pelo Sped (Sistema Público de Escrituração Digital) onde será realizado uma consulta em um único sistema onde conterá todas as informações imprescindíveis facilitando, assim, o cumprimento das obrigações principais e acessórias tributárias.

Com o Sped (Sistema Público de Escrituração Digita), o fisco pode também criar uma "malha fina", que possibilite o cruzamento das informações prestadas. Essa "malha fina" pode ser feita pela Receita Federal, Estado, Distrito Federal e Municípios, possibilitando a validação das informações e autuações das inconsistências não explicadas pelos contribuintes. (MARIANO; PERES, 2012, p.42)

É muito importante ter atenção na hora de passar às informações para o Sped, pois qualquer dado declarado incorretamente poderá acarretar em complicações com o Fisco. Como obrigação acessória, a empresa ao declarar o tributo no SPED deverá possuir obrigatoriamente uma assinatura digital na ECD (Escrituração Contábil Digital), na Escrituração Fiscal Digital e na NF-e (Nota Fiscal Eletrônica) para assegurar a validade jurídica do referido documento. Portanto, como garantia jurídica é necessário que todos os contribuintes, independentemente do porte da empresa adquiram 0 certificado digital.

A empresa ao transmitir seus dados para o SPED está se responsabilizando por todos os dados registrados no programa, sendo considerado como comprovante das atividades realizadas pela empresa, e se houver alguma incoerência com o que foi declarado, a referida empresa será autuada. Um exemplo de incoerência na declaração do SPED é o que ocorreu na Operação Lava Jato que por intermédio deste programa conseguiu formar provas o suficiente para iniciar uma investigação.

Sendo assim, o Compliance tributário é de grande importância para o ramo empresarial, tendo como finalidade evitar, identificar e prevenir as incoerências tributárias, visando à precaução de impropriedades com as normas tributárias. 


\section{CONSIDERAÇÕES FINAIS}

O Programa de Compliance ganhou notoriedade no Brasil através da Lei Anticorrupção que foi regulamenta pelo Decreto no 8.420/2015 e que prevê, em seu artigo 41, a inclusão de programa de integridade. Nesse sentido, o Programa de Compliance atuará conjuntamente à Lei Anticorrupção no caso de responsabilização de pessoas jurídicas.

As empresas que não se adequarem às normas estarão sujeitos a sanções. $O$ que poderá acarretar na responsabilização mesmo sem ter qualquer tipo de envolvimento com atos ilícitos.

Por essa lei ser recente, existe um percentual grande de pessoas e empresas que ainda não conhecem a Lei Anticorrupção, assim como não reconhecem o Programa de Compliance e nem a importância desse programa atuando com a lei. $\mathrm{O}$ que possibilita levar essa informação para aquelas pessoas e empresas que ainda não têm o conhecimento de qual é o papel do Compliance em relação à responsabilidade de pessoas jurídicas, quais são seus objetivos, e como ele pode ajudar na organização interna e externa das corporações de todos os setores.

Neste contexto, cujo objetivo foi o de compreender o programa de Compliance na determinação da responsabilidade jurídica no que tange a lei anticorrupção, foi verificado que o programa atuará em conjunto com a lei, à qual o programa se adaptará, bem como às condições de cada corporação, que ficará encarregada de criar o seu próprio programa de integridade.

Por não se tratar de um procedimento pronto, o programa de Compliance é uma ferramenta que a Lei Anticorrupção trouxe como instrumento de incentivo para que as empresas possam ter condutas éticas e, principalmente, combater a corrupção, levando a benefícios para as empresas e para a sociedade brasileira.

A Lei Anticorrupção busca responsabilização de pessoas jurídicas envolvidas com atos ilícitos e o programa de Compliance pode ajudar na determinação de responsabilidade de pessoas jurídicas, pois ele é uma ferramenta que tem como objetivo atuar nas organizações para evitar, identificar e prevenir qualquer tipo de condutas ilícitas. 
As empresas que não adotarem esse programa em sua estrutura interna e externa estão mais vulneráveis a sofrerem sanções e a terem sua imagem vinculada à corrupção perante a sociedade e futuros investidores ocasionando, fatalmente, perdas financeiras.

\section{REFERÊNCIAS}

AGUILLAR, Fernando Herren. Direito Econômico Do Direito Nacional ao Direito Supranacional. 5. ed. São Paulo: Atlas, 2016.

BADARÓ, Gustavo Henrique; BOTTINI, Pierpaolo Cruz. Lavagem de dinheiro: aspectos penais e processuais penais: comentários à Lei 9.613/1998, com as alterações da Lei 12.683/2012. 3. ed. São Paulo: Editora Revista dos Tribunais, 2016.

BRASIL, Presidência da República. Casa Civil. Subchefia para Assuntos Jurídicos. Regulamenta a Lei $n^{\circ}$ 12.846, 1ํ de agosto de 2013, que dispõe sobre a responsabilização administrativa de pessoas jurídicas pela prática de atos contra a administração pública, nacional ou estrangeira e da outras providências. Portal da Legislação, Brasília, mar. 1998. Disponível em: > http://www.planalto.gov.br/ccivil_03/_ato2015-2018/2015/decreto/d8420.htm<. Acesso em: 03 abr. 2019.

- Presidência da República. Casa Civil. Subchefia para Assuntos Jurídicos. Dispõe sobre a responsabilização administrativa e civil de pessoas jurídicas pela prática de atos contra a administração pública, nacional ou estrangeira, e dá outras providências. . Portal da Legislação, Brasília, mar. 1998. Disponível em: > http://www.planalto.gov.br/ccivil_03/_ato2011-2014/2013/lei/l12846.htm<. Acesso em: 08 out. 2018.

.CONSELHO ADMINISTRATIVO DE DEFESA ECONÔMICA (Cade) Disponível em: < http://www.cade.gov.br/>. Acesso em: 10 out.2018.

. MINISTÉRIO DA TRANSPARÊNCIA (CGU). Manual prático de avaliação de programa de integração em PAR. Brasília, 2018.

.MINISTÉRIO DA TRANSPARÊNCIA (CGU), Manual de responsabilização administrativa de pessoas jurídicas. Brasília, 2018.

.MINISTÉRIO DA TRANSPARÊNCIA E CONTROLADORIA-GERAL DA UNIÃO Disponível em: > http://www.cgu.gov.br/assuntos/responsabilizacao-de-empresas/leianticorrupcao<. Acesso: 03 out. 2018. 
BATISTA, Antenor. Corrupção: Fator de Progresso? 5.ed. São Paulo: Letras\&Letras.2000.

HERNANDES, Pedro Petronillio. Combate à Corrupção no Brasil: análise sob a ótica da economia da corrupção. Disponível em: <http://www.cgu.gov.br/Publicacoes/controle-social/arquivos/6-concurso-monografias2011.pdf $\geq$. Acesso em: 10 abr. 2019.

INSTITUTO BRASILEIRO DE DIREITO E ÉTICA EMPRESARIAL (IBDEE). Disponível em: > http://www.ibdee.org.br/Compliance-tributario/ <. Acesso em: 05 abr. 2019.

INSTITUTO BRASILEIRO DE GOVERNANÇA CORPORATIVA (IBGC) Disponível em: >https://www.ibgc.org.br/<. Acesso em: 05 abr. 2019.

MEDEIROS, Roberto; ROCHA, Leonino. A Corrupção no Brasil e no Mundo. Uane, 2016. Disponível em: > www.tce.ce.gov.br/downloads/Controle_Cidadao/gestao_publica/fasciculo_1_.pdf < . Acesso em: 10 set. 2018.

MENDES, Francisco; CARVALHO, Vinicius. Compliance, concorrência e combate à corrupção. São Paulo: Trevisan, 2017.

PESTANA, Marcio. Lei Anticorrupção: exame sistematizado da lei no 12.846/2013. São Paulo: Manole, 2016.

SANTOS. Fernanda Marinela et al. Lei anticorrupção: Lei $n^{\circ} 12.846$, de $1^{\circ}$ de agosto de 2013. São Paulo: Saraiva, 2015.

SILVA, Daniel Cavalcante; COVAC, José Roberto. Compliance como uma boa prática de gestão no ensino superior privado. São Paulo: Saraiva, 2015.

SILVEIRA, Renato de Mello; SAAD-DINIZ, Eduardo. Compliance, Direito penal e a lei anticorrupção. São Paulo: Saraiva 2015.

VEIRANOS, Advogados. Disponível em: <http://www.veirano.com.br/>. Acesso: 30 out. 2018.

VERRÍSIMO, Carla. Compliance incentivo à adoção de medidas anticorrupção. São Paulo: Saraiva, 2017. 